\title{
Performance of Flourosilicon Treated Protective Garment against Pesticides Residue Transmission
}

\author{
R. Prabhavathi*, D. Anitha and Jyothi Vastrad \\ Acharya N.G Ranga Agricultural University, Advanced Post Graduate Centre, \\ Lam, Guntur, Andhra Pradesh, India \\ *Corresponding author
}

\begin{abstract}
A B S T R A C T
A field-cum-laboratory study was conducted to understand the barrier performance of protective garment made from Polyester-Cotton fabric treated with water repellent silicon finish. Field study comprised of identifying the health problems encountered by pesticide sprayers in four villages viz., Narakoduru, Salapadu, Suddapalli and Vejendla of Chebrolu, mandal, Guntur District, Andhra Pradesh, where chilli crop is being cultivated in larger extent under high input management of insecticides. A blend of polyester/cotton (67:33) with 157.7 GSM was treated with BOND-WR-12 A (RTU) water repellent silicone finish and garment was constructed using the treated fabric. Transmission of pesticide residue onto the skin of applicator through treated fabric was studied with three toxic pesticides that are used in chilli cultivation in the selected villages. The transmission study of Phasphomidon, Monocrotophos and Dimethoate pesticides were individually carried out in field conditions following Wiping test (WHO, 2014 report). Covered and uncovered areas were created on the body of applicators using garment and wiping was done after pesticide application. The collected pesticide residues from the skin were analysed through Gas Chromatography. The study revealed that mean residue transmission in covered area was less.
\end{abstract}

Keywords

Flourosilicon

Treated Protective

Garment, Pesticides

Article Info

Accepted:

07 October 2020

Available Online:

10 November 2020

\section{Introduction}

In Andhra Pradesh chilli crop is being cultivated on commercial basis in an area of 1.3 lakh hectares with production of 7.7 lakhs tonnes and a revenue of Rs. 3563 crores per annum. India is ranked first in India for the production of red chillies. Among thirteen districts of Andhra Pradesh, Guntur is one of the important chilli growing district with an area of 66,896 hectares and 1.2 lakh tones production (Velayyutham and Damodaran,
2015). For obtaining higher yields farmers of this crop in Andhra Pradesh are using various pesticides for management of pest and diseases for maximum yield and earnings. As a result, chilli farmers are directly or indirectly exposed to pesticides and fungicides when mixing or when applying pesticides or when working in treated fields.

Application of chemical pesticides impacted their health, creating problems ranging from simple temporary conditions of headache to 
severe critical conditions such as cancer. Human skin is porous and absorbs greater amount of pesticide bringing out health issues. Lack of proper education and awareness, use of improper clothing, negligence on the part of worker, are the reasons for adverse health effects due to pesticides Chilli farmers of Guntur district are found to use some extremely and highly toxic pesticides as listed by WHO classification.

So, an attempt was made to develop garment made from blend of $\mathrm{P} / \mathrm{C}$ treated with silicone finish for good barrier performance that offers right protection and to study the efficacy of the fabric in blocking the transmission of pesticide residue onto skin.

\section{Materials and Methods}

\section{Fabric selection}

A blend of Polyester/Cotton provides comfort to the wearer as well reduces the pesticide penetration levels in the fabric (Padma and Khateeja, 2017). Hence, plain woven polyester/cotton (67:33) with 157.7 GSM was selected for the study.

\section{Desizing}

Fabric is desized for better penetration of finishing solution. Acid desizing was adopted (Karmarkar, 1999). Fabric was treated with dilute sulphuric acid with a concentration of $5-10 \mathrm{ml} / \mathrm{l}$ of water at a temperature of about $40^{\circ} \mathrm{C}$ for 3-4 hours in 'Soft Flow Dyeing' machine. Material to liquor ratio was kept at 1:20. After treatment, fabric was rinsed thoroughly in plain tap water.

\section{Selection of finish}

BOND -WR -12-A RTUa finish that is based on environmentally friendly C-6 chemistry was used. It is a water based formulation that forms a nano coat on the surface.

\section{Finishing parameters}

Water repellent finish was applied on fabric in pad-dry-cure with a finish conc. of $5 \%$, at $\mathrm{pH}$ 4.5. Wet pick up was maintained at $70 \%$. Drying temp. of $105^{\circ} \mathrm{C}$, Curing temp. of $165^{\circ} \mathrm{C}$ and time for both drying and curing was same i.e. $3 \mathrm{~min}$.

\section{Measuring dermal exposure using swabs}

Treated fabric was stitched into overalls and given to applicators to study the performance of the fabric. In this study, only the right-hand sleeve of the garment was folded above the elbow while the left hand sleeve was left without folding creating an uncovered and covered area on the applicator (Fig. 1). Area for collection of residues was marked (from $64 \mathrm{~cm}^{2}$ skin area) on both the hands on the upper surface of arms between elbow and wrist. Before spraying, marked uncovered and covered areas were cleaned two times with cotton wipes soaked in alcohol. Applicators were then asked to perform their routine spraying activity with difference in sleeve condition of the garment. Three pesticides, Monocrotophos, Dimethoate and Phosphamidon were sprayed using the same concentration as they use on the crop. After completing the activity, the same marked areas were swabbed five times each with absorbent pads. Collected swabs were stored separately and labelled until further analysis. Likewise, samples were collected for three spraying operation for all three pesticides. The same was carried out using control fabric.

\section{Analysis of residue in GC}

Collected swabs were soaked in $30 \mathrm{ml}$ of hexane, overnight in separate cleaned glass bottles with lids. The contents were shaken thoroughly and filtered through Whatman No.1 filter paper. The extracts of three pesticides individually from samples were 
later injected and analysed for the quantification of pesticides present in samples were expressed as $\mathrm{ng} / \mathrm{cm}^{2}$

\section{Results and Discussion}

Transmission of pesticide residues through treated fabric

The data pertaining to transmission of three pesticide residues from fabric to skin during application is presented in Table 1 and Fig. 2 . The Value in the parenthesis indicates \% decrease over control. The deposited pesticide residues on the skin of applicator were measured by collecting from $64 \mathrm{~cm}^{2}$ skin area marked on forearms. The residues from both covered (protective garment) and uncovered areas on the skin were collected and compared to identify the need for appropriate protective clothing against spraying. The transmission of residues was assumed to be due to rubbing of fabric to skin while spraying activity or by absorption of residues from fabric through perspiration (Rajitha and Vastala, 2003).

Table.1 Transmission of different pesticide residues through treated fabric

\begin{tabular}{|c|c|c|c|c|c|c|c|c|}
\hline \multirow{4}{*}{$\begin{array}{l}\text { Name of the } \\
\text { selected pesticide }\end{array}$} & \multicolumn{7}{|c|}{ No. of sprays } & \multirow{4}{*}{$\begin{array}{l}\text { Mean of } \\
\text { pesticide } \\
\text { residue } \\
\text { transmission }\end{array}$} \\
\hline & \multicolumn{7}{|c|}{ After application } & \\
\hline & 1 & 2 & 3 & $\begin{array}{c}\text { Fabric } \\
\text { type }\end{array}$ & 1 & 2 & 3 & \\
\hline & \multicolumn{3}{|c|}{ Uncovered area } & \multicolumn{4}{|c|}{ Covered area } & \\
\hline \multirow[t]{2}{*}{ Phosphamidon } & 1.28 & 2.61 & 3.5 & Control & $0.15(88.28)$ & $0.16(93.89)$ & $0.26(92.57)$ & \multirow[t]{2}{*}{1.293} \\
\hline & 1.26 & 2.59 & 3.52 & Treated & $0.04(96.83)$ & $0.08(96.91)$ & $0.11(97.16)$ & \\
\hline \multirow[t]{2}{*}{ Monocrotophos } & 1.3 & 2.57 & 3.58 & Control & $0.18(86.15)$ & $0.18(92.99)$ & $0.28(92.18)$ & \multirow[t]{2}{*}{$1.340 *$} \\
\hline & 1.26 & 2.71 & 3.56 & Treated & $0.09(92.86)$ & $0.09(96.68)$ & $0.12(96.91)$ & \\
\hline \multirow[t]{2}{*}{ Dimethoate } & 1.26 & 2.53 & 3.45 & Control & $0.15(88.10)$ & $0.07(97.24)$ & $0.25(93.04)$ & \multirow[t]{2}{*}{1.261} \\
\hline & 1.24 & 2.56 & 3.46 & Treated & $0.02(98.38)$ & $0.03(98.82)$ & $0.09(97.39)$ & \\
\hline $\begin{array}{l}\text { Average residue } \\
\text { transmission of } \\
\text { three exposures }\end{array}$ & \multicolumn{7}{|c|}{$\begin{array}{l}\text { Uncovered area }(1.333) \\
\text { Covered area }(1.267)\end{array}$} & - \\
\hline Mean of sprays & \multicolumn{7}{|c|}{ One (0.684), Two (1.350) and Three (1.845) } & - \\
\hline \multicolumn{7}{|c|}{$\begin{array}{l}\text { SEM; } 0.015811 \quad \text { SED; } 0.022361 \\
\text { degrees of freedom) }(*) \text { more significant. }\end{array}$} & \multicolumn{2}{|c|}{ t $5 \% 336$ dof $=1.967($ dof $=$} \\
\hline
\end{tabular}

Fig.1 Covered and uncovered areas on the forearm of applicator

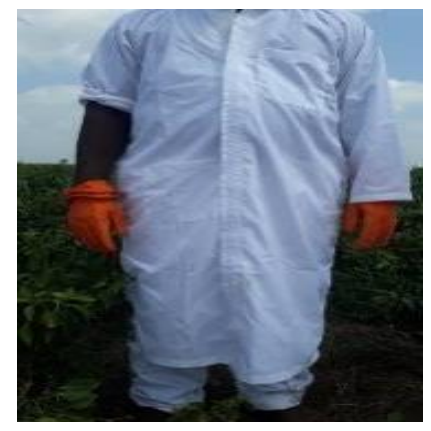


Fig. 2 Transmission of different pesticide residues through treated fabric

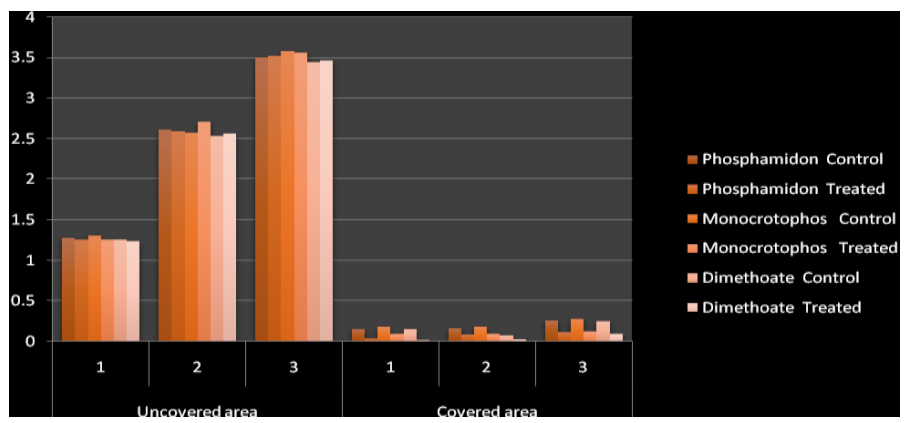

Applicator's skin covered with treated fabric gave good protection for all three pesticides though there was a continuous increase in the residue amount by the end of $3^{\text {rd }}$ spray. In case of Monocrotophos pesticide, covered skin with treated fabric, showed the same protection after the first and $2^{\text {nd }}$ sprays however very slight increase was observed after $3^{\text {rd }}$ spray. It is evident from the table 1 that uncovered areas, after each spray showed higher values than covered areas. Higher values were observed with Monocrotophos pesticide after $1^{\text {st }}, 2^{\text {nd }}$ and third spraying over the other two pesticides.

In conclusions the present study it was observed that, the treated protective garment transmitted less the pesticide residue over ordinary clothing. The treated garment obstructed the pesticide residues transmission. So, it can reduce the hazardous effects on the health of the applicators. Further, applicator's skin covered with treated fabric gave good protection for all three pesticides though there were continuous increases in the residue amount by the end of $3^{\text {rd }}$ spray. In case of Monocrotophos pesticide, with regards to covered skin with treated fabric, there was the same protection provided after the first and $2^{\text {nd }}$ sprays however very slight increase was observed after $3^{\text {rd }}$ spray.

\section{References}

Karmakar, S.R. 1999. Chemical Technology in the pre-treatment Processes of textiles. Textile Science and Technology. 12(1): 497.

Padma A and Khateeja S. K. 2017. Improving farmers knowledge on indigenous practice of spraying pesticides in grape garden. International Journal of Agricultural Science an research. 7(6): 189-200.

Rajitha, I and Vatsala, R. 2003. Effectiveness of protective clothing for agricultural workers. Research Gate.

Velayutham, L.K and Damodaran, K. 2015. Growth Rate of Chilli Production in Guntur District of Andhra Pradesh. International Journal of Research in Humanities and Social Studies. 2( 11): 1-5. WHO, 2014 report

\section{How to cite this article:}

Prabhavathi, R., D. Anitha and Jyothi Vastrad. 2020. Performance of Flourosilicon Treated Protective Garment against Pesticides Residue Transmission. Int.J.Curr.Microbiol.App.Sci. 9(11): 440-443. doi: https://doi.org/10.20546/ijcmas.2020.911.054 